\title{
Incidence of pulmonary disease caused by mycobacteria other than tuberculosis in British Columbia
}

\author{
R Kevin Elwood MB BCh MRCP (UK) FRCPC ${ }^{1}$, Anabelle M Opazo Saez PhD², \\ Vittorio Lentini BSc MD MHSc ${ }^{3}$, Ramak Shadmani MD MSc ${ }^{1}$
}

RK Elwood, AM Opazo Saez, V Lentini, R Shadmani. Incidence of pulmonary disease caused by mycobacteria other than tuberculosis in British Columbia. Can Respir J 2002;9(5):319-323.

CONTEXT: The incidence of pulmonary disease due to mycobacteria other than tuberculosis (TB) in Canada has not been documented.

OBJECTIVE: To determine the incidence of pulmonary disease due to mycobacteria in the nonimmunocompromised population of British Columbia.

DESIGN: A retrospective cohort study of 110 cases of mycobacteria infection other than TB identified from 1991 to 1995.

SETTING: British Columbia Centre for Disease Control, Division of TB Control.

RESULTS: The overall incidence rate of infection with mycobacteria other than TB was $0.63 \times 10^{-5} /$ year. This incidence rate was significantly higher among women (relative risk $[R R]=2$, $\mathrm{P}=0.0006)$ and in those aged 55 years or older $(\mathrm{RR}=8$, $\mathrm{P}<0.00001$ ). In contrast with $\mathrm{TB}$, patients were more frequently born in Canada $(\mathrm{P}<0.00001)$ or in industrialized countries other than Canada $(\mathrm{P}<0.00001)$, and were less likely to be Aboriginal
$(\mathrm{P}=0.0007)$ or foreign born from Asia $(\mathrm{P}<0.0001)$. The most common organism isolated in British Columbia was Mycobacterium avium-intracellulare (82.7\%). Overall, 78 (71\%) cases had underlying lung disease. Drug intolerance was very common (42\%). After treatment, $55 \%$ and $41 \%$ of the patients were rendered smear negative or culture negative, respectively. Radiological improvement was noted in $55 \%$ of patients, and $60 \%$ of patients responded symptomatically to treatment.

CONCLUSIONS: The overall incidence of pulmonary disease is low. It is a disease predominantly of women 55 years and older, and targets completely different ethnic groups than TB, suggesting a protective effect of infection with Mycobacterium tuberculosis. $M$ avium-intracellulare was the most common pathogen isolated. Further investigation is required into the natural history of so-called 'colonizers'. Considerable morbidity may be prevented with earlier intervention.

Key Words: Incidence rate; Mycobacteria infection other than tuberculosis

${ }^{1}$ British Columbia Centre for Disease Control Society, Division of Tuberculosis Control, Vancouver, British Columbia; ${ }^{2}$ Indiana University School of Medicine, Department of Cellular and Integrative Physiology, Indianapolis, Indiana, USA; ${ }^{3}$ National Defense, Force Health Protection, Communicable Disease Control, Ottawa, Ontario

Correspondence and reprints: Dr R Kevin Elwood, Division of Tuberculosis Control, British Columbia Centre for Disease Control, 655 W 12th Avenue, Vancouver, British Columbia V5Z 4R4. Telephone 604-660-6102, fax 604-660-1950, e-mail kevin.elwood@bccdc.ca 


\section{Incidence de la maladie pulmonaire causée par les mycobactéries autres que la tuberculose en Colombie-Britannique}

CONTEXTE : L'incidence de la maladie pulmonaire attribuable aux mycobactéries autres que la tuberculose (TB) n'a pas été documentée. OBJECTIF : Déterminer l'incidence de la maladie pulmonaire due à des mycobactéries dans une population non immunodéprimée de la Colombie-Britannique.

MODÈLE : Étude de cohorte rétrospective portant sur 110 cas d'infections mycobactériennes autres que la TB identifiées entre 1991 et 1995.

LIEU : British Columbia Centre for Disease Control, division de la lutte contre la tuberculose.

RÉSULTATS : Le taux d'incidence globale d'infection par des mycobactéries autres que la TB a été de $0,63 \times 10^{-5} / \mathrm{an}$. Cette incidence s'est révélée significativement plus élevée chez les femmes (risque relatif [RR] $=2, \mathrm{p}=0,0006)$ et chez les sujets de 55 ans ou plus $(\mathrm{RR}=8, \mathrm{p}<0,00001)$. Contrairement à la TB, cette maladie s'observait plus souvent chez les
Canadiens de souche $(\mathrm{p}<0,00001)$ ou dans les pays industrialisés autres que le Canada $(\mathrm{p}<0,00001)$ et étaient moins susceptibles d'être des Autochtones $(p=0,007)$ ou des immigrants venus d'Asie $(p<0,0001)$. L'agent le plus fréquemment isolé en Colombie-Britannique a été Mycobacterium avium-intracellulaire (82,7 \%). Dans l'ensemble, 78 (71\%) des cas présentaient des maladies pulmonaires sous-jacentes. L'intolérance aux médicaments a été très fréquente $(42 \%)$. Après le traitement, $55 \%$ et $41 \%$ des patients respectivement ont eu des résultats de frottis ou de cultures négatifs. Des améliorations radiologiques ont été notées chez $55 \%$ des patients et $60 \%$ des patients ont répondu au traitement sur le plan des symptômes.

CONCLUSION : L'incidence globale de maladie pulmonaire est faible. Cette maladie affecte surtout les femmes de 55 ans et plus et s'attaque à des groupes ethniques très différents de ceux qui sont touchés par la TB, ce qui suggère un effet protecteur de l'infection à Mycobacterium tuberculosis. M. avium intracellulaire a été l'agent pathogène le plus souvent isolé. D'autres recherches sont nécessaires sur le plan de l'histoire naturelle des "pseudo-colonisateurs". Une morbidité considérable pourrait être prévenue si les interventions étaient appliquées plus tôt.
A lthough considered a reluctant pathogen, mycobacteria other than tuberculosis (TB) (MOTT), also referred to as non-TB mycobacteria, are capable of causing pulmonary disease, even in those with no demonstrable defect in their immune system. The disease favours those with damaged airways caused by chronic obstructive pulmonary disease, bronchiectasis, tuberculosis and interstitial disease such as pneumoconiosis $(1,2)$. It is less easy to explain the occurrence of the disease in those without predisposing airway pathology, although some studies suggest a genetic susceptibility (3-5). Suggestions have been made that the number of patients with pulmonary disease due to MOTT has been increasing in the United States (6) and Japan (7). The disease is not reportable, and therefore, incidence rates are difficult to calculate and follow longitudinally. The incidence of the disease in Canada has not been documented.

The British Columbia Centre for Disease Control (BCCDC), Vancouver, maintains a centralized TB control service responsible for the treatment of TB throughout the province and has close links with the provincial laboratory. A centralized pharmacy, also housed within the BCCDC, supplies drugs for treatment of typical mycobacterial disease for all patients in British Columbia. The drug regimens used for the treatment of pulmonary disease due to MOTT overlap with those regimens used to treat typical $\mathrm{TB}$, and the common drugs are supplied from this pharmacy. This unique centralized service provided an opportunity to identify all persons with disease due to MOTT being treated between 1991 and 1995 in British Columbia, and thus, aid in the attempt to provide meaningful incidence rates for future comparisons.

\section{PATIENTS AND METHODS}

The Division of TB Control in British Columbia maintains a computerized database of all cases of active pulmonary TB. The BCCDC also maintains a centralized pharmacy that is the sole supplier of medication used to treat patients with $\mathrm{TB}$ and the antituberculous medication prescribed to treat MOTT patients. Because antituberculous medications are a standard part of regimens used to treat disease caused by MOTT, all such cases can be identified in British Columbia. Each case was reviewed, and those who were immunocompromised or had extrapulmonary disease were excluded. To distinguish between disease and colonization, the American Thoracic Society criteria (8) were used to identify a patient. All patients had to be symptomatic, and have radiological evidence consisting of any of the following: airspace disease or cavitations with or without nodules or nodules alone present for more than two months who had three positive cultures, with or without positive smears; or any lung biopsy that grew MOTT. Progressive bronchiestasis with multiple small nodules found on high resolution computerized tomographic scanning was also accepted as a case. Exclusion was made of any other lung disease to explain the x-ray changes. Being placed on treatment was not a prerequisite for being included in the study. Patients were initially thought to have TB. When cultures grew MOTT and the physician continued treatment, despite non-TB cultures, it was taken as proof that the physician was not mistakenly treating TB. The date of diagnosis was defined as the date of a positive culture result. Data concerning age, sex, country of birth, health region, organisms isolated, presence of pectus excavatum, associated lung disease, drug therapy, drug reactions and response to treatment were collected.

The country of birth of MOTT cases $(n=110)$ was compared with cases of Mycobacterium tuberculosis infection diagnosed in $1995(\mathrm{n}=311)$.

\section{Statistical analysis}

The incidence rates of MOTT in British Columbia were estimated as a whole and in each health region. Age-specif- 


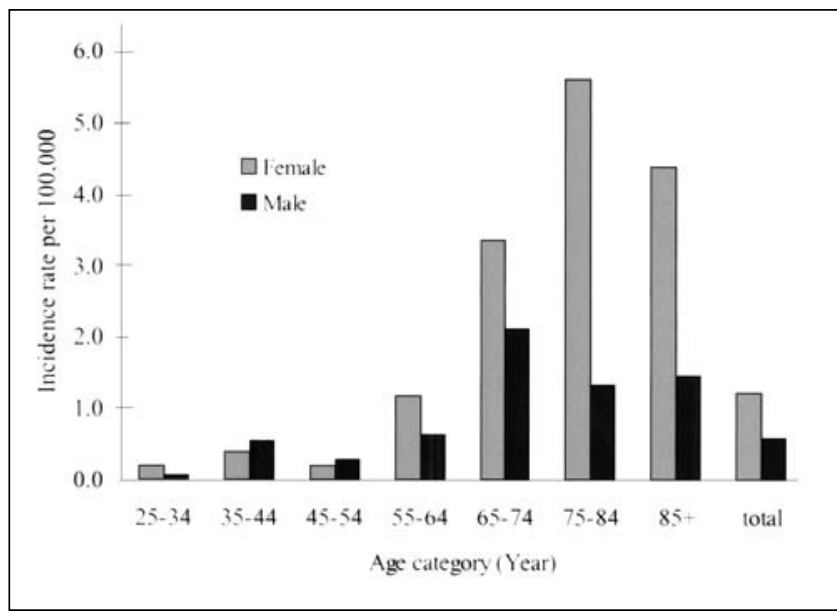

Figure 1) Incidence rates of pulmonary disease caused by mycobacteria other than tuberculosis in British Columbia. Rates according to age and sex, 1991 to 1995

ic rates were also calculated for both sexes. The population time at risk was calculated by multiplying the average population of each health region of British Columbia during the study period by the duration of the study. The incidence rates were estimated by dividing the number of new cases of MOTT by this denominator. The comparison of incidence rates was completed with the Normal theory test. Population figures, for the relevant years of the study period, were based on the information provided by Statistics Canada (http://www.bestat.gov.bc.ca/data/pop/pop/BCpop 3.htm [version current September 12, 2002]).

The comparison of proportions was performed with Fisher's exact test.

\section{RESULTS}

Between 1991 and 1995, 110 cases of MOTT were identified. The incidence rates of MOTT per year were calculated for British Columbia and each health region. The incidence rate of MOTT did not change significantly over the study period (ranging from $0.55 \times 10^{-5} /$ year in 1994 to $0.71 \times 10^{-5}$ /year in $1995, \mathrm{P}=0.2$ ).

The overall incidence rate was $0.6 \times 10^{-5} /$ year. Incidence rates were highest among residents of the southern and central interior of British Columbia (1.1 and 1.2, respectively) and a suburb of metropolitan Vancouver (Burnaby 1.32).

The incidence rate of MOTT was significantly higher in women $(\mathrm{RR}=2, \mathrm{P}=0.0006)$ and in cases age 55 years or older $(\mathrm{RR}=8, \mathrm{P}<0.00001)$ (Figure 1).

Table 1 shows the distribution of MOTT and TB patients according to the birthplace. MOTT cases, compared with TB cases, were more frequently born in Canada ( $44 \%$ versus $18 \%, \mathrm{P}<0.00001)$ or in industrialized countries other than Canada (17\% versus $4 \%, \mathrm{P}<0.00001$ ), and were less frequently Aboriginal ( $1 \%$ versus $13 \%, \mathrm{P}=0.0007$ ). Foreignborn patients from Asia were more likely to have TB (57\% versus $15 \%, \mathrm{P}<0.0001)$. The country of birth was not recorded in $22 \%(n=24)$ of the MOTT cases.

\begin{tabular}{|c|c|c|c|}
\hline Birth place & $\begin{array}{c}\text { MOTT cases } \\
(n=110)(\%)\end{array}$ & $\begin{array}{l}\text { TB cases } \\
(n=311)(\%)\end{array}$ & $\mathbf{P}$ \\
\hline Canada & 44 & 18 & $<0.00001$ \\
\hline Canada - Aboriginal & 1 & 13 & 0.0007 \\
\hline Industrialized countries & 17 & 4 & $<0.00001$ \\
\hline United Kingdom & 7 & 1 & \\
\hline United States & 3 & 1 & \\
\hline $\begin{array}{l}\text { Other industrialized } \\
\text { countries }\end{array}$ & 7 & 2 & \\
\hline Eastern Europe & 0 & 1 & 0.6 \\
\hline Asia & 15 & 57 & $<0.0001$ \\
\hline China & 7 & 16 & \\
\hline Hong Kong & 4 & 7 & \\
\hline Other parts of Asia & 5 & 34 & \\
\hline Africa and/or Latin America & 1 & 4 & 0.1 \\
\hline Unknown & 22 & 4 & \\
\hline
\end{tabular}

The most common organism identified in British Columbia was Mycobacterium avium-intracellulare isolated in $83 \%$ of cases (Table 2). Mycobacterium kansasii was the next most common organism isolated (7\%), followed by Mycobacterium xenopi (4\%) and Mycobacterium chelonae $(4 \%)$. More than one atypical isolate was found in three patients.

Overall, 78 (71\%) cases had underlying lung disease. Chronic obstructive pulmonary disease was present in 38\% of cases, bronchiectasis in $28 \%$ and TB in $14 \%$. Asthma (8\%), bullous disease (4\%) and interstitial lung disease (3\%) were less frequent findings.

The majority of cases reviewed received treatment directed at the atypical organism $(n=105,95 \%)$. The most common drugs used were antituberculous medications (isonizid, rifampin, pyrazinamide) $(\mathrm{n}=60,55 \%)$. Forty-five patients $(41 \%)$ received anti-tuberculous therapy combined with other drugs including a macrolide (17\%), quinolones and clofazamine $(9 \%)$, clofazamine $(4 \%)$, macrolide and quinolones $(4 \%)$, quinolones $(3 \%)$, or another combination of these drugs (4\%). One patient received treatment with a macrolide and quinolones. Four cases $(4 \%)$ were not put on treatment: one of whom died soon after diagnosis; one refused to be treated; one case discontinued treatment after a few days due to drug intolerance; and one for whom no reason was not recorded. The duration of treatment varied considerable ranging from 0 to 116 weeks (mean 39.4 , median 36). After treatment, $55 \%$ of the cases were rendered smear negative and $41 \%$ of the cases were rendered culture negative.

Drug intolerance was defined as any of the following adverse reactions: nausea, vomiting, diarrhea, increase in liver enzymes, abnormal blood count, blurred vision and 
TABLE 2

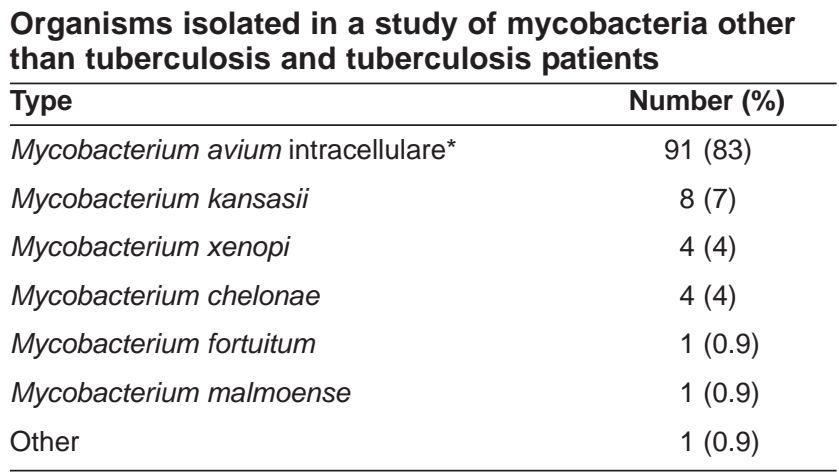

${ }^{*}$ Three specimens were positive for two organisms, $\mathrm{M}$ avium-intracellulare plus $\mathrm{M}$ chelonae, $\mathrm{M}$ fortuitum or $\mathrm{M}$ scrofulaceum

fever. Drug intolerance was common, occurring in $42 \%$ of the cases.

Radiological improvement was noted in $55 \%$ of cases, while $17 \%$ showed no change and $6 \%$ had worsened by the end of treatment. Some $60 \%$ of patients responded symptomatically to treatment. A lateral $\mathrm{x}$-ray was available for review in 96 cases (87\%). Pectus excavatum was seen in $16 \%$ of cases.

\section{DISCUSSION}

The centralized nature of TB control in British Columbia offers a unique opportunity to identify cases of pulmonary disease attributable to MOTT in nonimmunocompromised patients. All isolates that grow MOTT organisms are reported to the Division of TB Control, and the overlap antituberculous medication used for patients' treatments is supplied by a central pharmacy located at the BCCDC. Thus, every case treated in the province can be reliably identified. Clearly, these cases do not represent every case in the province. Our methods favour the identification of treated cases and probably underestimate the true incidence rate of MOTT in nonimmunocompromised individuals. We are confident that the cases identified are patients with lung disease caused by these organisms rather than so-called 'colonizers'.

There are relatively few reports of the incidence of MOTT. O'Brien et al (9) reported in 1987 the results of a national survey carried out in the United States; they described a rate of $1.28 / 100,000$ for $M$ avium. These reports included pulmonary and extra pulmonary disease, and largely excluded AIDS patients $(9,10)$. No similar Canadian national reports have been published.

A previous study of cases in British Columbia published in 1985 (11) showed that, between 1972 and 1981, 109 cases of patients with pulmonary disease due to atypical organisms were identified. The authors suggested that there was an upward trend in the number of cases, paralleled by an increase in the number of isolates from tissue, or from two or more sputum specimens. We collected 110 cases over five years, which may represent a true increase in incidence compared with the previous study or, more likely, may represent an increasing awareness among physicians of the dis- ease or an increased willingness to attempt treatment. We did not, however, identify a significant increase in the incidence of the disease over the five years, although there was some variation from $0.55 \times 10^{-5}$ in 1994 to a high of $0.71 \times 10^{-5}$ in 1995 .

We observed variations in the incidence rate of MOTT according to health regions (range 0.19 to $1.32 \times 10^{-5} /$ year). The health regions differ not only by geography and climatic conditions but also by the demographic characteristics, such as age and ethnicity, of the residents. The ability of the local physicians to consider and diagnose the disease would also influence the rates. Further investigation are required to explain the observed differences.

The most common organism identified in British Columbia, as in the previous study, remains $M$ avium-intracellulare followed by $M$ kansasii, which responds more readily to treatment that other MOTT organisms, and the rapid growers, $M$ chelonae and $M$ fortuitum. We had a single case of $\mathrm{M}$ malmoense, which was reported as the first case observed in Canada (12). The MOTT organism most likely to cause disease varies considerably with geographical location. While $M$ avium-intracellulare is the most common organism causing disease in British Columbia, $M$ xenopi predominates south eastern Ontario, and $\mathrm{M}$ malmoense is the most common isolate in Scotland and northern Europe (13). The geographical variation in the isolates responsible for pulmonary disease has been well documented but remains largely unexplained. More than one organism may be isolated from a single case, as occurred in three of our cases.

Pulmonary disease due to MOTT was formally reported to be a disease of men occurring in the sixth decade of life, favouring those with pre-existing lung conditions. Our data show that this description does not represent the cases seen in British Columbia, where it is a disease of elderly women (incidence rate for women 55 years or older $3.1 \times 10^{-5} /$ year versus an incidence rate for men 55 years and older $1.3 \times 10^{-5}$ /year, $\left.\mathrm{P}=0.0004\right)$. Other authors have commented on this changing pattern of disease (14). The form of disease occurring in women appears to favour the lingula or middle lobe and occurs largely in nonsmokers with no predisposing underlying lung diseases (10). These patients have noncavitary disease, nodules and focal bronchiectasis identified by computed tomography scan (15).

The majority of our cases had predisposing underlying lung diseases, but of interest, $29 \%$ of the cases did not. A yet to be described defect in local defense mechanisms or genetic susceptibility may explain why these relatively nonvirulent organism occasionally cause considerable disease in this latter group (3-5).

Pectus excavatum was identified visually in $16 \%$ of cases compared with $27 \%$ of cases recorded by Iseman et al (16), who formally measured the anterior border of the vertebral bodies to the posterior surface of the lower sternum. This was significantly more common than in a group of patients with TB (5\%) and in the general population (2.4\%). The 
significance of skeletal abnormalities is uncertain, but it may be a phenotypic marker of patients prone to pulmonary disease due to MOTT.

There was a striking contrast in ethnicity in those with MOTT versus those with TB. It was distinctly uncommon in Aboriginals and other groups known to have a high rate of $\mathrm{TB}$, suggesting that sensitization to TB may have a protective effect (17).

The majority of our patients (95\%) were treated for the disease. Five per cent of the cases placed on treatment did not fulfill our criteria to be included as a case. This high rate of treatment reflects the methods that are used to identify patients.

The threshold for initiating treatment of a case may well be lowered in the future, with an increasing realization among physicians that the organism is associated with specific syndromes in what appear to be normal hosts, largely elderly women. The increased use of computed tomography scans has identified a group of patients who formally would not have been considered eligible for treatment. Further, there is increasing evidence that the nodules associated with bronchiectasis are caseating granulomas and, thus, evidence of disease, and predict culture positivity for $\mathrm{M}$ avium (15). Although it was formally assumed that bronchiectasis leads to colonization with atypical organisms, there is evidence to suggest that these organisms may well be capable of causing bronchiectasis (18). Peribronchial granuloma formation caused by $M$ avium complex infection has been seen from large airways to bronchioles. Clearly, the natural history of what is termed 'colonization' needs to be defined. If it can be convincingly demonstrated that colonization precedes and causes bronchiectasis, earlier preventative strategies may well be an option. With current recommended regimens consisting of rifampin or rifabutin, ethambutol and a macrolide, initiation of early treatment would be an expensive undertaking, considering the large numbers of patients likely to meet the criteria. A recently completed randomized trial of treatment for pulmonary disease caused by MOTT organisms (19) did not include a macrolide but only recorded a cure rate of $30 \%$ at five years for those with $M$ avium complex infection. Macrolide-containing regimens are poorly tolerated and expensive. If individual factors that predict response to conventional antituberculous medication or disease progression can be identified, a less expensive regimen may prevent the future development of lung damage caused by these organisms. Proof of this concept will require prospective, placebo controlled trials.

\section{CONCLUSIONS}

We found the overall incidence rate of MOTT in the province of British Columbia to be $0.63 \times 10^{-5} /$ year. MOTT is a disease that affects all age groups, but is predominantly a disease of women older than 55 years and targets different ethnic groups than TB. There is emerging evidence that 'colonization' with these organisms may well be instrumental in causing disease, raising the possibility that considerable morbidity may be avoided with earlier treatment.

\section{REFERENCES}

1. Rosenwig DY. Pulmonary mycobacterial infection due to mycobacterium intracellulare-avium complex: clinical features and course in 100 consecutive cases. Chest 1979;75:115-9.

2. O'Brien RJ, Geiter LJ, Synder DE. The epidemiology of non-tuberculous mycobacterium in the United States. Am Rev Respir Dis 1997;135:1007-14.

3. Tanaka E, Kimoto T, Matsumoto H, et al. Familial pulmonary Mycobacterium avium complex disease. Am J Respir Crit Care Med 2000;161:1643-7.

4. Takahashi M, Ishizaka A, Nakamura H, et al. Specific HLA in pulmonary MAC infection in a Japanese population. Am J Respir Crit Care Med 2000;162:316-8.

5. Kubo K, Yamazaki Y, Hanaoka M, et al. Analysis of HLA antigens in Mycobacterium avium-intracellulare pulmonary infection. Am J Respir Crit Care Med 2000;161:1368-71.

6. Prince DS, Huston DD, Steiner RN, et al. Infection of Mycobacterium avium complex in patients without predisposing conditions. N Engl J Med 1989;321:863-8.

7. Kubo KY, Yamazaki T, Hachiya M, Hoyasaka T, Honda M, Hasegawa Sone S. Mycobacterium avium-intracelulare infection in patients without known pre-disposing lung disease. Lung 1998;176:381-9.

8. Diagnosis and treatment of disease caused by nontuberculous mycobacteria. Am J Respir Crit Care Med 1997;156:1-25S.

9. O'Brien RJ, Geiter OJ, Snider DE. Epidemiology of non-tuberculosis mycobacterial diseases in the United States. Result of a National Survey. Am Rev Respir Dis 1987;135:1007-14.

10. Reich JM, Johnson RE. Mycobacterium avium complex pulmonary disease. Incidence, presentation and response to therapy in a community setting. Am Rev Respir Dis 1991;143:1381-5.

11. Isaac-Renton JL, Allen EA, Chao CW, Grzybowski S, Wittaker EI, Black WA. Isolation and geographic distribution of mycobacteria other than M tuberculosis in British Columbia 1972-1981. CMAJ $1985 ; 133: 573-609$

12. Al-Momari MS, Black W, Elwood K. Pulmonary disease due to Mycobacterium malmoense in British Columbia. Can Respir J 1998;5:135-8.

13. Falkinham JO 3rd. Epidemiology of infection by nontuberculous mycobacteria. Clin Microbial Rev 1996;9:177-215.

14. Kennedy TP, Webber DJ. Non-tuberculous mycobacteria: an under appreciated cause of geriatric lung disease. Am J Respir Crit Care Med 1994;149:1654-8.

15. Swensen SJ, Hartman TE, Williams DE. Computed tomographic diagnosis of Mycobacterium avium-intracellulare complex in patients with bronchiectasis. Chest 1994;105:49-52.

16. Iseman MD, Buschman DL, Ackerson LM. Pectus excavatum and scoliosis, thoracic anomalies associated with pulmonary disease caused by Mycobacterium avium complex. Am Rev Respir Dis 1991;144:914-6.

17. Trnka L, Dankova D, Svandova E. Six years' experience with the discontinuation of BCG vaccination. 4. Protective effect of BCG vaccination against the Mycobacterium avium intracellulare complex. Tuber Lung Dis 1994;75:348-52.

18. Fujita J, Ohtsuki Y, Suemitsu I, et al. Pathological and radiological changes in resected lung specimens in Mycobacterium avium-intracellulare complex disease. Eur Respir J 1999;13:532-40.

19. Research Committee of the British Thoracic Society. First randomised trial of treatments for pulmonary disease caused by $M$ aviumintracellulare, $M$ malmoense and $M$ xenopi in HIV negative patients: rifampin, ethambutol and isoniazid versus rifampin and ethambutol. Thorax 2001;56:167-72 


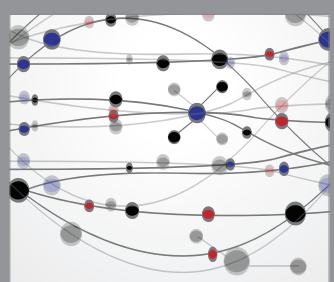

The Scientific World Journal
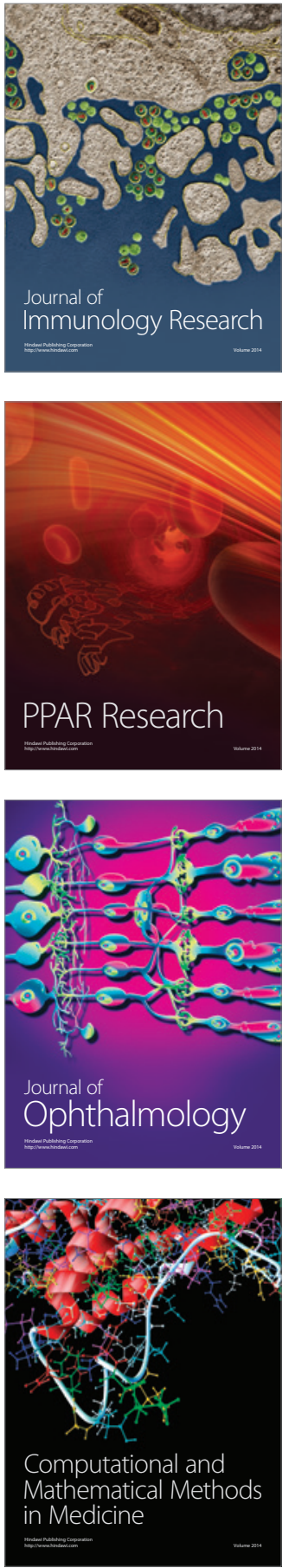

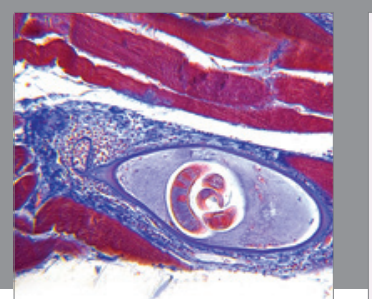

Gastroenterology Research and Practice

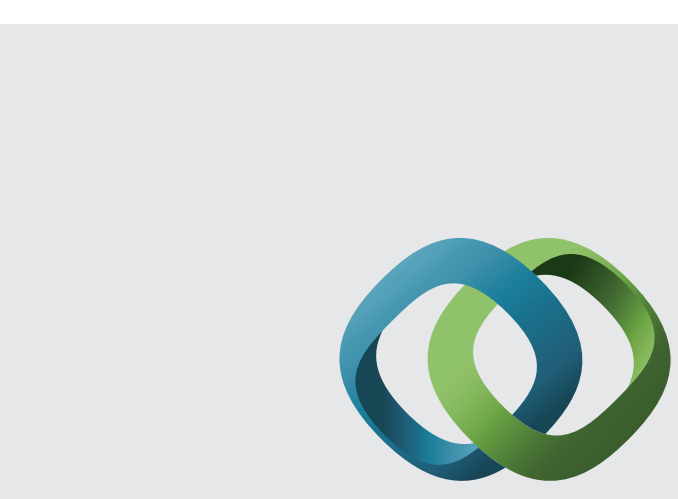

\section{Hindawi}

Submit your manuscripts at

http://www.hindawi.com
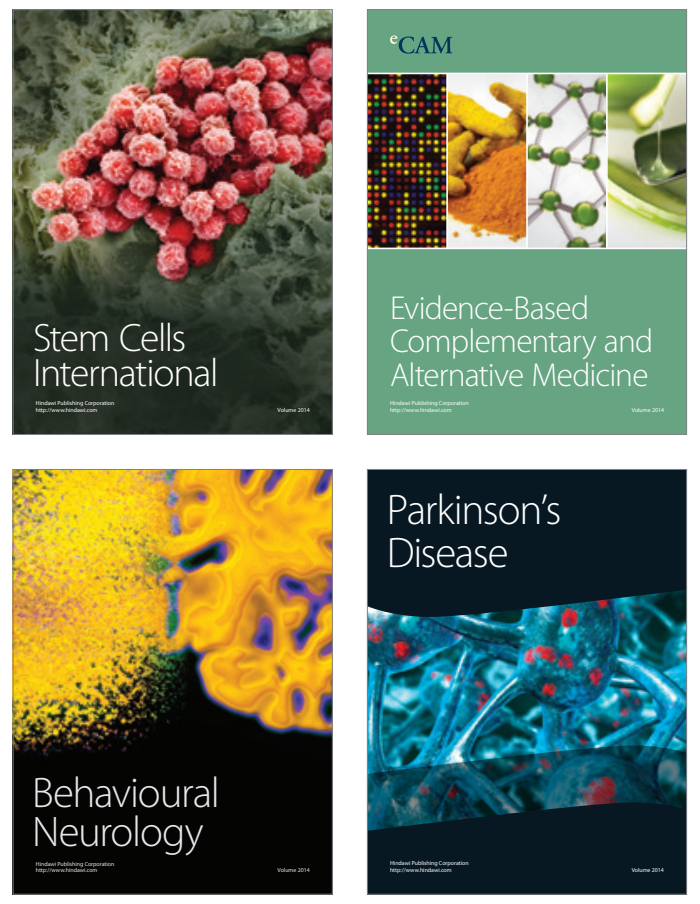
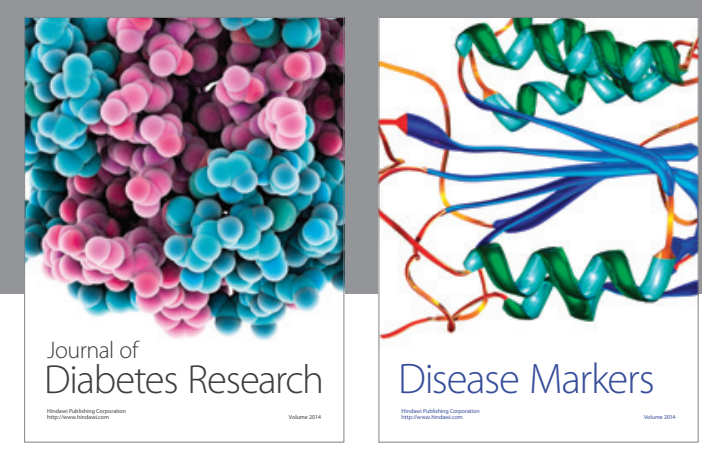

Disease Markers
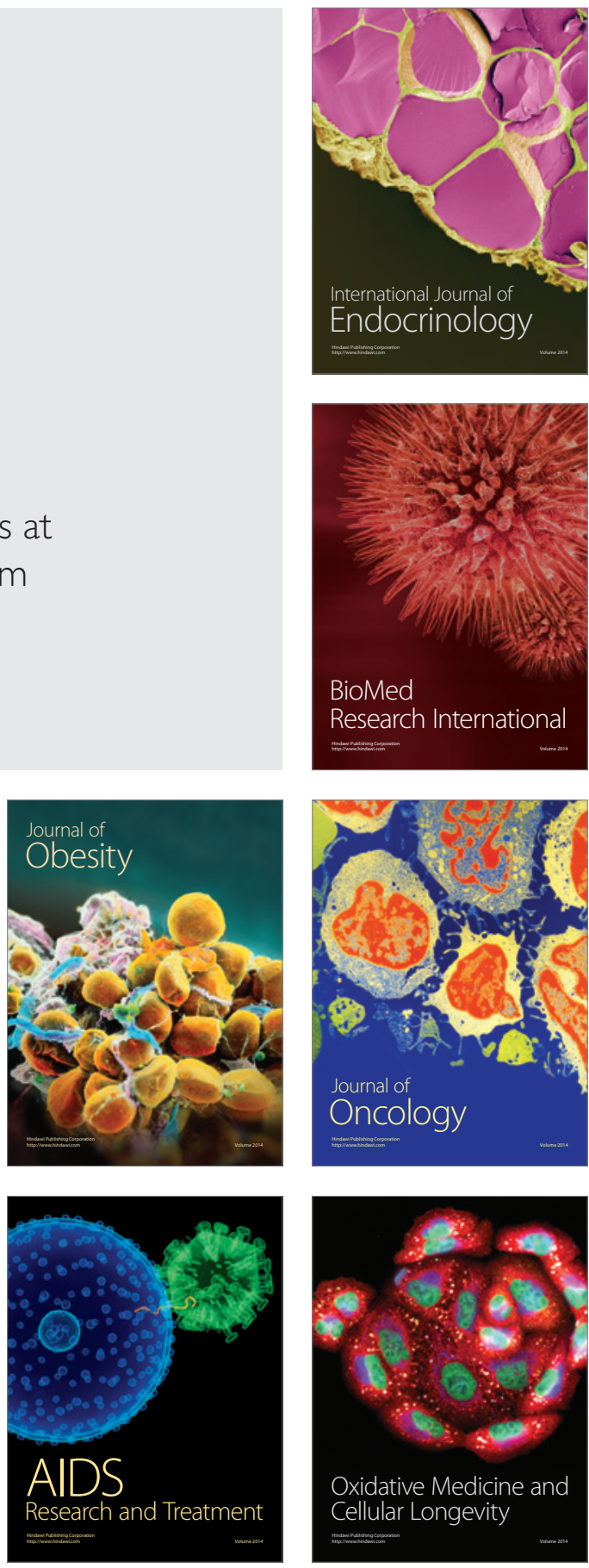